\title{
Acute Abdomen and Multisystem Inflammatory Syndrome in Children with COVID-19: A Case Report and Review of Pathophysiology, Gastrointestinal Symptoms and Abdominal Radiology
}

\author{
Noela Carrera-Guermeur ${ }^{{ }^{*}}$, Rosa-María Martín-Crespo-Izquierdo ${ }^{1}$, Hilda-Josefa Ramírez-Velandia ${ }^{1}$, María-Esmeralda \\ Kuan-Argüiello ${ }^{1}$, Mónica Bernabéu-Rodríguez ${ }^{2}$, Pilar Zamarrón-Fuertes ${ }^{3}$, Natalia Ramos-Sánchez ${ }^{4}$ and Rafael Luque- \\ Mialdea $^{1}$ \\ ${ }^{I}$ Department of Pediatric Surgery, Complejo Hospitalario Universitario de Toledo, Toledo, Spain \\ ${ }^{2}$ Department of Radiology, Complejo Hospitalario Universitario de Toledo, Toledo, Spain \\ ${ }^{3}$ Department of Microbiology, Complejo Hospitalario Universitario de Toledo, Toledo, Spain \\ ${ }^{4}$ Department of Pediatrics, Pediatric Intensive Care Unit, Complejo Hospitalario Universitario de Toledo, Toledo, Spain
}

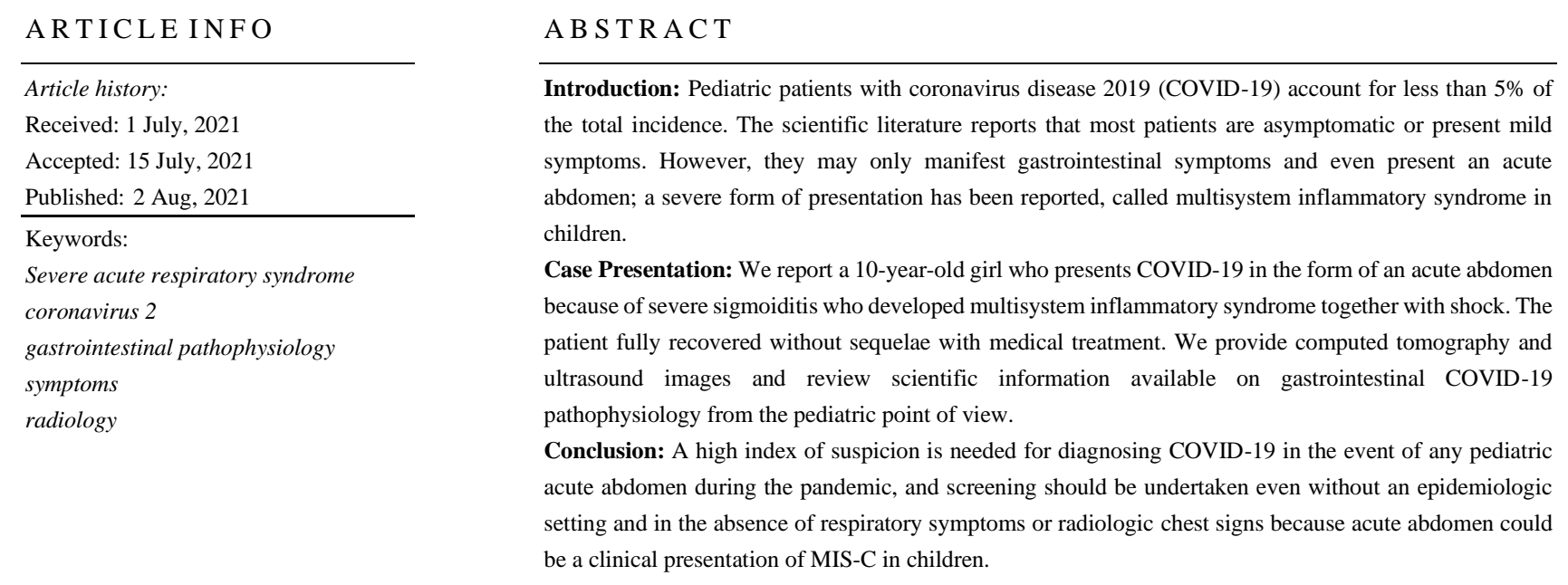

(C) 2021 Noela Carrera-Guermeur. Hosting by Science Repository.

Introduction

According to updated data from World Health Organization, there has been an overall total of 181.521.067 confirmed cases and 3.937.437 deaths globally since onset of the current COVID-19 pandemic in December 2019 caused by the "Severe Acute Respiratory Syndrome Coronavirus 2" (SARS-CoV-2). Since the onset of the pandemic, children represented $14.2 \%$ of total cumulated cases according to the American Academy of Pediatrics. Mortality is exceptional [1]. Hospital and pediatric intensive care unit (PICU) admission in pediatrics varies between $5.7-20 \%$ and $0.58-2 \%$ respectively, and PICU mortality is lower than $5 \%$; significantly lower than the $50-62 \%$ reported in adults $[2,3]$.

The most common symptoms in children, just as for adults, are cough $(48.5 \%)$ and fever (41.5\%), and prevalence of gastrointestinal symptoms are also similar $(9.6 \%)[4,5]$. However, a series of 204 adult patients has been reported where $50.5 \%$ presented gastrointestinal symptoms [6]. It is notable that these symptoms may be the only manifestations of the disease. Clinical presentation can be as diverse as mesenteric adenitis,

*Correspondence to: Dr. Noela Carrera-Guermeur, M.D., Department of Pediatric Surgery, Complejo Hospitalario Universitario de Toledo, Avenida de Barber, No 30, 45004, Toledo, Spain; Tel: +34925269295; Fax: +34925254113; E-mail: noelacarrera@hotmail.com 
symptoms mimicking acute appendicitis (leading to unnecessary laparotomies) and even intestinal ischaemia [7-9]. In COVID-19 adult patients, the occurrence of gastrointestinal symptoms appears to be associated with a more severe course and even higher mortality [10]. The Centers for Disease Control and Prevention (CDC) issued a notification in May 2020 about a new pediatric clinical condition associated with COVID-19 denominated multisystem inflammatory syndrome (MIS-C) and set out diagnostic criteria (Table 1) [11]. It has been reported that this syndrome may condition critical course of the disease [12].

\section{Case Presentation}

A 10-year-old girl without any previous disease or history of exposure to COVID-19 came to our emergency department with a five-day history of abdominal pain, fever of $38^{\circ} \mathrm{C}$, headache and vomiting. Examination revealed a good general condition and bilateral lower quadrant pain with abdominal guarding. Laboratory results are summarized in (Table 1). Given the suspected acute abdomen, abdominal ultrasound (US) was performed (Figure 1A). Sigmoiditis was diagnosed without ruling out the diagnostic possibility of acute appendicitis because the cecal appendix was not observed, whereby the patient was admitted to the pediatric surgery department. In accordance with our COVID-19 pandemic protocol, we screened for SARS-CoV-2. Nasopharyngeal swab sample was tested using a real-time reverse transcriptionpolymerase chain reaction (rRT-PCR) assay. The result was positive, whereby the study was completed with a chest $\mathrm{X}$-ray; this was normal.

Table 1: Laboratory parameters. Centers for Disease Control and Prevention diagnostic criteria of Multisystem Inflammatory Syndrome in Children (abnormal findings are bold lettered) [11].

\begin{tabular}{|c|c|c|c|}
\hline Laboratory parameters & Reference range & $\begin{array}{l}\text { In the emergency } \\
\text { department }\end{array}$ & At PICU admission \\
\hline Haemoglobin $(\mathrm{g} / \mathrm{dL})$ & $12-15$ & 12.4 & 10.9 \\
\hline Platelet count $($ per $\mu \mathrm{L})$ & $120000-400000$ & 270000 & 193000 \\
\hline White-cell count (per $\mu \mathrm{L}$ ) & $5000-14500$ & 12000 & 6500 \\
\hline Lymphocyte count (per $\mu \mathrm{L})$ & $2500-8500$ & 400 & 200 \\
\hline Neutrophil count $($ per $\mu \mathrm{L})$ & $1800-7700$ & 10500 & 5700 \\
\hline C-reactive protein $(\mathrm{mg} / \mathrm{L})$ & $1-5$ & 147 & 224.5 \\
\hline Procalcitonin $(\mathrm{ng} / \mathrm{mL})$ & $<0.5$ & - & 1.09 \\
\hline Prothrombin activity $\%$ & $70-150$ & 56 & 54 \\
\hline International normalized ratio & $0.6-1.3$ & 1.5 & 1.5 \\
\hline Fibrinogen $(\mathrm{mg} / \mathrm{dL})$ & $150-600$ & 945 & 708 \\
\hline D-Dimer $(\mathrm{ng} / \mathrm{mL})$ & $0.0-500$ & - & 7084 \\
\hline Interleukin-6 (pg/mL) & $150-600$ & - & 734.9 \\
\hline Ferritin $(\mathrm{ng} / \mathrm{mL})$ & $15-150$ & - & 188 \\
\hline N-terminal B-type natriuretic peptide (pg/mL) & $\begin{array}{l}\text { Patients with acute dyspnea } \mathrm{N} \text {-terminal B-type } \\
\text { natriuretic peptide: } \\
\text { Heart failure unlikely }<300 \\
\text { Heart failure very likely } \\
<50 \text { years }>450 \\
50-75 \text { years }>900 \\
->75 \text { years }>1800\end{array}$ & - & 1353 \\
\hline Troponin I (ng/mL) & $0.000-0.120$ & - & $<0.012$ \\
\hline
\end{tabular}

Centers for Disease Control and Prevention. Case Definition for Multisystem Inflammatory Syndrome in Children (diagnostic criteria are bold lettered) [8].

An individual aged $<21$ years presenting fever $\left(\geq 38.0^{\circ} \mathrm{C}\right.$ for $\geq 24$ hours, or report of subjective fever lasting $\geq 24$ hours), laboratory evidence of inflammation (including, but not limited to, one or more of the following: an elevated C-reactive protein, erythrocyte sedimentation rate, fibrinogen, procalcitonin, D-Dimer, ferritin, lactic acid dehydrogenase, or Interleukin-6, elevated neutrophils, reduced lymphocytes and low albumin), and evidence of clinically severe illness requiring hospitalization, with multisystem $(\geq 2)$ organ involvement (cardiac, renal, respiratory, hematologic, gastrointestinal, dermatologic or neurologic); and

No alternative plausible diagnoses; and

Positive for current or recent SARS-CoV-2 infection by real-time polymerase chain reaction, serology, or antigen test; or COVID-19 exposure within the 4 weeks prior to the onset of symptoms. 

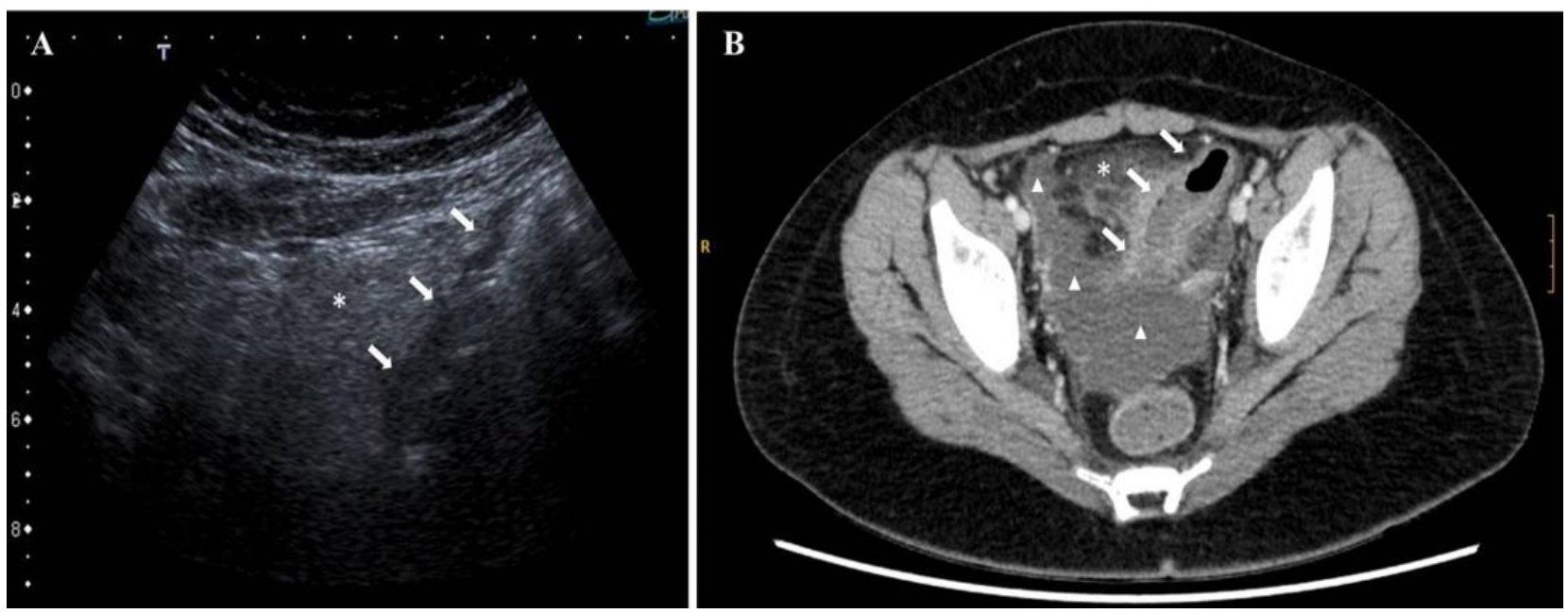

Figure 1: A) Abdominal US. Segmental wall thickening involving the sigmoid colon, concentric and uniform (white arrows). Hyperechoic mesenteric fat (asterisk), related to inflammatory changes. B) Abdominal contrast-enhanced CT (portal venous phase), axial image. Pronounced segmental concentric wall thickening of the sigmoid colon (white arrows). Severe surrounding fat stranding (asterisk) and moderate amount of free fluid (triangle).

The pain subsided, but the patient presented fever of $38^{\circ} \mathrm{C}$, diarrhea and pruritic macular rash of the trunk. On day 2 of admission, she presented sudden clinical worsening with lethargy, fever, tachycardia (150 beats per minute) with blood pressure at the lower limit of normal (systolic blood pressure $107 \mathrm{~mm} \mathrm{Hg}$ /diastolic blood pressure $54 \mathrm{~mm} \mathrm{Hg}$ ), oliguria and mild metabolic acidosis. Given the suspicion of MIS-C with shock associated with COVID-19, she was admitted to the PICU. Electrocardiogram and echocardiography were normal. Laboratory results are summarized in (Table 1). Other etiology was ruled out with a full serology and body fluid cultures. The patient received vasopressor support (noradrenaline $0.1 \mathrm{mcg} / \mathrm{kg} / \mathrm{min}$ ), antibiotics for suspected abdominal bacterial co-infection (ceftriaxone $50 \mathrm{mg} / \mathrm{kg} / 24 \mathrm{~h}$ and metronidazole $\quad 10 \quad \mathrm{mg} / \mathrm{kg} / 8 \mathrm{~h}), \quad$ COVID-19 treatment (hydroxychloroquine $6.5 \mathrm{mg} / \mathrm{kg} / 12 \mathrm{~h} 4$ doses; low-molecular-weight heparin $0.5 \mathrm{mg} / \mathrm{kg} / 12 \mathrm{~h}$; vitamin $\mathrm{K} 10 \mathrm{mg} /$ dose), and MIS-C treatment (interleukin-6 inhibitor (tocilizumab) $8 \mathrm{mg} / \mathrm{kg} / 24 \mathrm{~h} 1$ dose; intravenous immune globulin $2 \mathrm{~g} / \mathrm{kg} / 24 \mathrm{~h} 1$ dose; methylprednisolone $2 \mathrm{mg} / \mathrm{kg} / 24 \mathrm{~h} 1$ dose). The study was completed with abdominal computed tomography (CT) (Figures 1B, 2A \& 2B). We observed radiologic signs of severe acute sigmoiditis, homogeneous splenomegaly of $140 \mathrm{~mm}$ and mild bilateral pleural effusion with passive atelectasis of lung parenchyma but no parenchymatous involvement characteristic of COVID-19 in the lower thorax included in the CT.
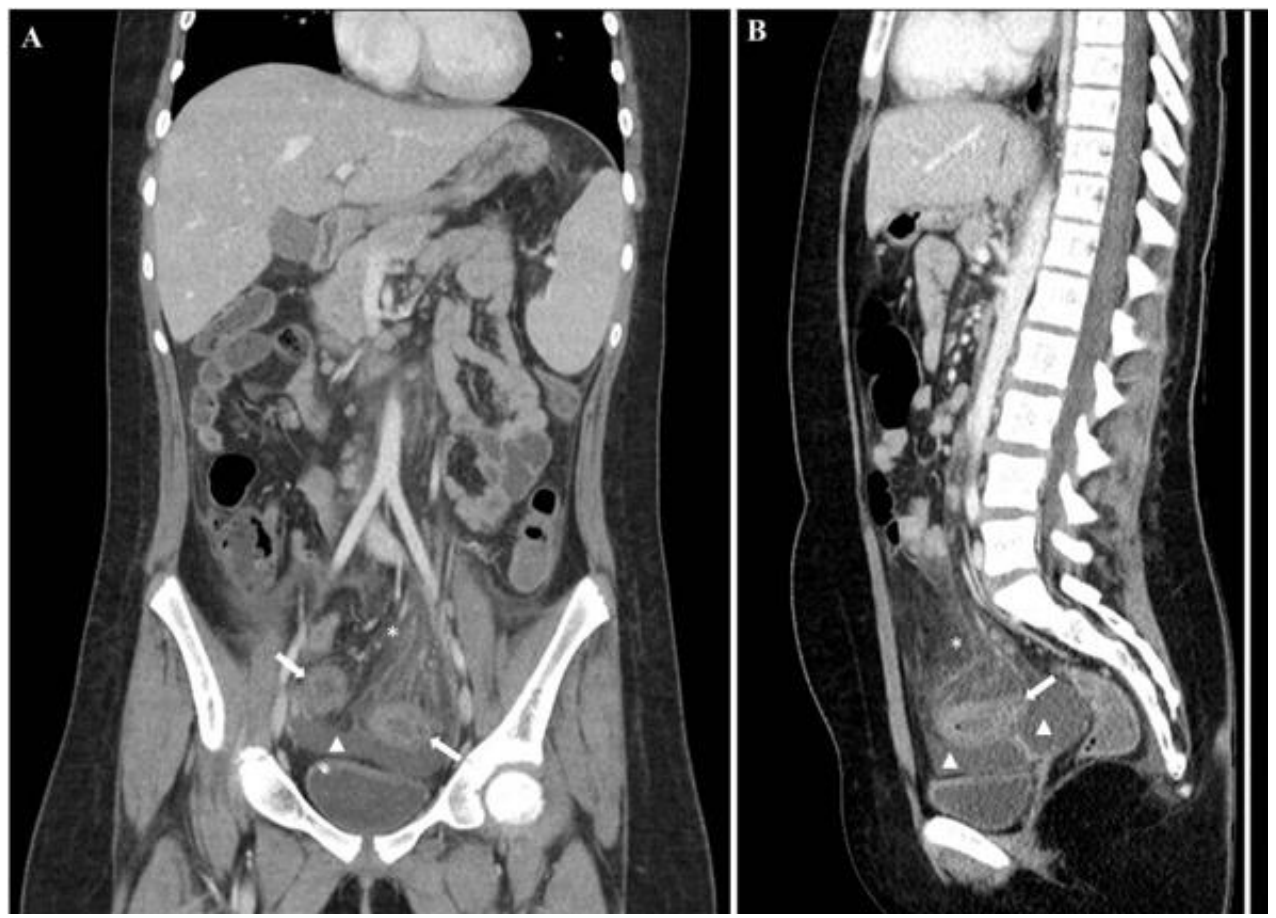

Figure 2: A) Abdominal contrast-enhanced CT (portal venous phase), coronal image. B) Abdominal contrast-enhanced CT (portal venous phase), sagittal image. Segmental concentric wall thickening of the sigmoid colon, with marked proximal involvement (white arrows). Pericolonic fat stranding and comb sign (engorgement of the vasa recta), as signs of inflammatory changes (asterisk). Pelvic free fluid (triangle). 
Given the clinical and radiologic worsening, the antibiotic protocol was switched to meropenem $(40 \mathrm{mg} / \mathrm{kg} / 8 \mathrm{~h})$ and vancomycin $(10 \mathrm{mg} / \mathrm{kg} / 6 \mathrm{~h})$. The patient was kept on a nil-per-mouth regimen with parenteral nutrition and close clinical monitoring. The clinical course was favourable with gradual normalization of the clinical and analytical picture. Bowel movements returned on the fourth day of PICU admission, and the patient returned to the ward after 8 days. Control CT was performed 11 days after first scan with frank radiologic improvement of sigmoiditis, and resolution of pleural effusion and splenomegaly. Oral intake resumption was uneventful, and the patient was discharged from hospital 17 days after admission.

Nasopharyngeal swab specimens were tested for SARS-CoV-2 with rRT-PCR on day 6 of admission (positive), day 11 (negative), day 13 (positive) and day 16 (negative). Anal swabs and stools were tested with the same methods on day 17 of admission (negative in both samples). The anal swab was tested again one week from discharge, which was also negative. Serologic SARS-CoV-2 study with chemiluminescence immunoassay 10 days from discharge revealed positive Immunoglobulin $\mathrm{G}$ and negative Immunoglobulin M. Family members, all asymptomatic, were investigated. The mother had a negative rRT-PCR on nasopharyngeal swab, and the patient's father and brother had positive Immunoglobulin $\mathrm{G}$ on serology. After one month of follow-up, the patient was asymptomatic, with a normal contrast enema ruling out postsigmoiditis stenosis.

\section{Discussion}

According to the American Academy of Pediatrics, since the pandemic began, 4,032,782 children with COVID-19 have been reported. Children represented $14.2 \%$ of all cases, with an overall rate of 5,358 cases per 100,000 children in the population. We have reviewed the available bibliography in English, Spanish and French on PubMed concerning COVID-19 from the perspective of pathophysiology, gastrointestinal symptoms and abdominal radiology. While we found some similar cases to the one reported by our group, radiology images are still scarce. Our case manifested as an acute abdomen exclusively with gastrointestinal symptoms in a 10-year-old girl, with severe bowel involvement which we illustrate with US and CT (Figures 1 \& 2). The patient developed MIS-C (Table 1), with four of the most common systems-organs (gastrointestinal, cardiovascular, hematologic and cutaneous) involved, and recovered without sequelae with medical treatment [11].

SARS-CoV-2 infects human cells by means of angiotensin-converting enzyme 2 (ACE2), that works as a functional receptor [13]. This receptor is highly expressed in lung epithelium (mainly in type II pneumocytes), small intestine epithelium, muscularis propria and muscularis mucosae from stomach to colon, vascular endothelium and vascular smooth muscle [14]. The relative protection of children against coronavirus appears to be accounted for by the fact that ACE2 expression in the nasal epithelium, which represents the initial point of entry of SARS-CoV-2, is age-dependent. Expression is much lower in children than adults and within the pediatric age range, there is less expression the lower the age [15]. This greater ACE2 expression in older children could explain MIS$\mathrm{C}$ being more common among patients with an average age of 8.3 years [12]. Other reasons that might explain the lower incidence of COVID19 in children are less exposure to the virus as a result of the lockdown of the population arising from the pandemic; lower frequency of comorbidities, absence of toxic habits and higher innate immunity [16].

The pathophysiology of intestinal injury during SARS-CoV-2 infection has been explained by three possible methods; direct damage because of active infection of the gastrointestinal tract, damage as a consequence of vascular phenomena (direct endothelial damage or infection-associated coagulopathy or thrombosis) and immune-mediated inflammatory damage $[6,17,18]$. Our patient exclusively presented gastrointestinal involvement, which might be because the gastrointestinal tract may be a target organ, although it could also be the first symptom of MIS-C, with immune-mediated intestinal damage [5, 12]. From a radiologic point of view, findings in pediatric abdominal imaging are beginning to be reported (Table 2), but the available published images are still very few [19-21].

Table 2: Abdominal US and CT imaging findings reported in COVID-19 and/or MIS-C in children (in decreasing order of frequency) [19-21].

\begin{tabular}{|l|l|}
\hline US Abdominal Findings (\%) & TC Abdominal Findings (\%) \\
\hline Mild ascitis (53-75\%) & Mild ascites (50-80\%) \\
\hline Mesenteric lymphadenopathy (47\%) & Mesenteric lymphadenopathy (60-100\%) \\
\hline Echogenic kidneys (63\%) & --- \\
\hline Mild hepatomegaly (75\%) & Mild hepatomegaly (50\%) \\
\hline Hyperechoic expanded mesenteric fat (37\%) & Mesenteric fat stranding (60\%) \\
\hline Mild splenomegaly (13\%) & Mild splenomegaly (50\%) \\
\hline Urinary bladder wall thickening (13\%) & Urinary bladder wall thickening (50\%) \\
\hline Bowel wall thickening (21\%) & Bowel wall thickening (20-50\%) \\
\hline Pericholecystic edema (16\%) & Pericholecystic edema (40\%) \\
\hline Periportal echogenicity (16\%) & Periportal edema (40\%) \\
\hline Gallbladder wall thickening (16-38\%) & Gallbladder wall edema (---) \\
\hline Gallbladder sludge (16\%) & --- \\
\hline
\end{tabular}




\begin{tabular}{|l|l|}
\hline Subcapsular splenic infarct (10\%) & Subcapsular splenic infarct $(20 \%)$ \\
\hline Edematous pancreatitis & --- \\
\hline Acute appendicitis & --- \\
\hline
\end{tabular}

In our case, US revealed hyperechoic pelvic mesenteric fat related to inflammatory changes and concentric wall thickening of the sigmoid colon (Figure 1A). However, acute appendicitis could not be ruled out because the cecal appendix was not visible. CT performed after clinical worsening revealed marked concentric parietal thickening of sigmoid colon suggesting acute inflammatory-infectious sigmoiditis, increased density and trabeculation of adjacent and retroperitoneal fat, engorgement of the vasa recta (comb sign), lymph node swelling and a moderate amount of intra-abdominal fluid in relation to marked inflammatory changes; ileocecal appendix was normal (Figures 1B, 2A \& 2B).

The CDC confirmed isolation of infectious SARS-CoV-2 in feces [22]. Although we were unable to detect SARS-CoV-2 in either our patient's anal swab or stool, prolonged RNA shedding has been reported in children, including those who have recovered and have a negative nasopharyngeal swab PCR [23]. This could mean that fecal-oral transmission of SARS-CoV-2 is possible along with the consequent epidemiologic and public health implications this entails; this is even more relevant in children. We are aware of the limitations a case report entails. However, we wish to take advantage of our experience to provide COVID-19 abdominal radiology, and we review the scientific information available on pathophysiology, gastrointestinal symptoms and abdominal imaging of COVID-19 in children. We also wish to highlight the importance of screening for SARS-CoV-2 in the event of any pediatric acute abdomen during the pandemic, even without an epidemiologic setting in the environment and in the absence of respiratory symptoms or radiologic chest signs compatible with COVID19 , because acute abdomen could be a clinical presentation of MIS-C in children.

\section{Author Contributions}

Dr. Carrera-Guermeur and Dr. Kuan-Argüello devised the entire project and the main conceptual ideas, analysed data, drafted the initial manuscript and reviewed and critically revised the final version of the manuscript. Dr. Martín-Crespo-Izquierdo and Dr. Ramírez-Velandia carried out acquisition of data, performed medical literature search both from the medical and surgical points of view, contributed to the initial manuscript and revised it critically for intellectual content. Dr. Bernabéu-Rodríguez substantially contributed to the work conception and design, critically reviewed all the clinical case images and chose the ones we published. She also wrote footnotes and revised the manuscript critically for important intellectual content from the radiologic point of view. Dr. Zamarrón-Fuertes advised us from a microbiological point of view and contributed to the acquisition and analysis of data, and she personally processed our patient's samples. She also performed the microbiological bibliographic search and critically revised the manuscript for important intellectual content from the microbiological perspective. Dr. Ramos-Sánchez treated the patient during her PICU admission, contributed to the work conception, advised us on the relevant clinical insights of the case and critically revised the manuscript for important intellectual content. Dr. Luque-Mialdea, Head of the Department of Pediatric Surgery, provided encouragement to review the clinical case and literature. He contributed to the conception and design of the work and revised it critically for important intellectual content.

\section{Consent for Publication}

Consent to publish was obtained from child's parent.

\section{Conflicts of Interest}

None.

\section{Funding}

None.

\section{Abbreviation}

ACE2: Angiotensin Converting Enzyme 2

CDC: Centers for Disease Control and Prevention

CT: Computed Tomography

COVID-19: Coronavirus Disease 2019

MIS-C: Multisystem Inflammatory Syndrome in Children

PICU: Pediatric Intensive Care Unit

rRT-PCR: Real-time Reverse Transcription Polymerase Chain Reaction

SARS-CoV-2: Severe Acute Respiratory Syndrome Coronavirus 2

US: Ultrasound

\section{REFERENCES}

1. Ludvigsson JF (2020) Systematic review of COVID-19 in children shows milder cases and a better prognosis than adults. Acta Paediatr 109: 1088-1095. [Crossref]

2. CDC COVID-19 Response Team (2020) Coronavirus disease 2019 in children - United States, February 12-April 2, 202 Coronavirus Disease 2019 in Children - United States, February 12-April 2, 2020. MMWR Morb Mortal Wkly Rep 69: 422-426. [Crossref]

3. Shekerdemian LS, Mahmood NR, Wolfe KK, Riggs BJ, Ross CE et al. (2020) Characteristics and Outcomes of Children With Coronavirus Disease 2019 (COVID-19) Infection Admitted to US and Canadian Pediatric Intensive Care Units. JAMA Pediatr 174: 868-873. [Crossref]

4. Lu X, Zhang L, Du H, Zhang J, Li YY et al. (2020) SARS-CoV-2 Infection in Children. N Engl J Med 382: 1663-1665. [Crossref]

5. Rokkas $\mathrm{T}$ (2020) Gastrointestinal involvement in COVID-19: a systematic review and meta-analysis. Ann Gastroenterol 33: 355-365. [Crossref]

6. Pan L, Mu M, Yang P, Sun Y, Wang R et al. (2020) Clinical Characteristics of COVID-19 Patients With Digestive Symptoms in 
Hubei, China: A Descriptive, Cross-Sectional, Multicenter Study. Am J Gastroenterol 115: 766-773. [Crossref]

7. Noda S, Ma J, Romberg EK, Hernandez RE, Ferguson MR (2021) Severe COVID-19 initially presenting as mesenteric adenopathy. Pediatr Radiol 51: 140-143. [Crossref]

8. Tullie L, Ford K, Bisharat M, Watson T, Thakkar H et al. (2020) Gastrointestinal features in children with COVID-19: an observation of varied presentation in eight children. Lancet Child Adolesc Health 4: e19-e20. [Crossref]

9. Khesrani LS, Chana K, Sadar FZ, Dahdouh A, Ladjadj Y et al. (2020) Intestinal ischemia secondary to Covid-19. J Pediatr Surg Case Rep 61: 101604. [Crossref]

10. Lee IC, Huo TI, Huang YH (2020) Gastrointestinal and liver manifestations in patients with COVID-19. J Chin Med Assoc 83: 521523. [Crossref]

11. Emergency preparedness and response: multisystem inflammatory syndrome in children (MIS-C) associated with coronavirus disease 2019 (COVID-19). Centers Dis Control Preven.

12. Feldstein LR, Rose EB, Horwitz SM, Collins JP, Newhams MM et al. (2020) Multisystem Inflammatory Syndrome in U.S. Children and Adolescents. N Engl J Med 383: 334-346. [Crossref]

13. Hoffmann M, Kleine Weber H, Schroeder S, Krüger N, Herrler T et al. (2020) SARS-CoV-2 Cell Entry Depends on ACE2 and TMPRSS2 and Is Blocked by a Clinically Proven Protease Inhibitor. Cell 181: 271.e8280.e8. [Crossref]

14. Hamming I, Timens W, Bulthuis MLC, Lely AT, Navis GJ et al. (2004) Tissue distribution of ACE2 protein, the functional receptor for SARS coronavirus. A first step in understanding SARS pathogenesis. J Pathol 203: 631-637. [Crossref]
15. Bunyavanich S, Do A, Vicencio A (2020) Nasal Gene Expression of Angiotensin-Converting Enzyme 2 in Children and Adults. JAMA 323 : 2427-2429. [Crossref]

16. Lee PI, Hu YL, Chen PY, Huang YC, Hsueh PR (2020) Are children less susceptible to COVID-19? J Microbiol Immunol Infect 53: 371 372. [Crossref]

17. Xiao F, Tang M, Zheng X, Liu Y, Li X et al. (2020) Evidence for Gastrointestinal Infection of SARS-CoV-2. Gastroenterology 158: 1831.e3-1833.e3. [Crossref]

18. Bhayana R, Som A, Li MD, Carey DE, Anderson MA et al. (2020) Abdominal Imaging Findings in COVID-19: Preliminary Observations. Radiology 297: E207-E215. [Crossref]

19. Hameed S, Elbaaly H, Reid CEL, Santos RMF, Shivamurthy V et al. (2021) Spectrum of Imaging Findings at Chest Radiography, US, CT, and MRI in Multisystem Inflammatory Syndrome in Children Associated with COVID-19. Radiology 298: E1-E10. [Crossref]

20. Blumfield E, Levin TL, Kurian J, Lee EY, Liszewski MC (2021) Imaging Findings in Multisystem Inflammatory Syndrome in Children (MIS-C) Associated With Coronavirus Disease (COVID-19). AJR Am J Roentgenol 216: 507-517. [Crossref]

21. Biko DM, Ramirez Suarez KI, Barrera CA, Banerjee A, Matsubara D et al. (2021) Imaging of children with COVID-19: experience from a tertiary children's hospital in the United States. Pediatr Radiol 51: 239247. [Crossref]

22. Xiao F, Sun J, Xu Y, Li F, Huang X et al. (2020) Infectious SARSCoV-2 in Feces of Patient with Severe COVID-19. Emerg Infect Dis 26: 1920-1922. [Crossref]

23. Xu Y, Li X, Zhu B, Liang H, Fang C et al. (2020) Characteristics of pediatric SARS-CoV-2 infection and potential evidence for persistent fecal viral shedding. Nat Med 26: 502-505. [Crossref] 